\title{
AS DIMENSÕES DOS PRODUTOS INTELIGENTES: UM ESTUDO EXPLORATÓRIO A PARTIR DA PERCEPÇÃO DOS USUÁRIOS DE SMARTPHONES
}

\author{
SMART PRODUCTS DIMENSIONS: AN EXPLORATORY \\ STUDY FROM USERS' PERCEPTION OF SMARTPHONE
}

\section{Ivandro Cecconello}

Mestre em Engenharia de Produção pela Universidade Federal de Santa Catarina (Florianópolis/Brasil).

Professor na Universidade de Caxias do Sul (Caxias do Sul/Brasil).

E-mail: ivandrocecconello@gmail.com

\section{Vanessa de Campos Machado}

Mestra em Administração pela Universidade de Caxias do Sul (Caxias do Sul/Brasil).

Professora no Instituto Federal de Educação, Ciência e Tecnologia do Rio Grande do Sul (Bento Gonçalves/Brasil).

E-mail: machadv@miamioh.edu

\section{Gabriel Sperandio Milan}

Pós-Doutor em Administração pela Universidade Federal do Rio Grande do Sul (Porto Alegre/Brasil).

Professor no Centro de Ensino Superior Cenecista de Farroupilha (Farroupilha/Brasil).

E-mail: gabmilan@terra.com.br 


\section{RESUMO}

O presente trabalho teve como objetivo explorar a percepção das dimensões-chave percebidas pelos usuários de produtos inteligentes que são: autonomia, capacidade de aprender, reatividade, capacidade de cooperação, interação humana e personalidade. Para tanto, foi realizada uma pesquisa qualitativa, por meio de 15 entrevistas em profundidade utilizando questionário semiestruturado. Para análise de conteúdo das entrevistas em profundidade foi utilizado software Nvivo Plus. A análise de cluster revelou a relação entre as dimensões habilidade para cooperar e interação humana, bem como a dimensão autonomia com habilidade para aprender. Como principais resultados, pode-se afirmar que este trabalho resultou em maior entendimento da percepção das seis dimensões-chave bem como sua relação, frequência e importância para os usuários. Além disso, identificou-se três dimensões adicionais: segurança, desempenho e status, sendo a dimensão status um resultado da percepção integrada de todas as outras dimensões.

Palavras-chave: Produtos Inteligentes. Smartphone. iPhone. Dimensões-chave dos produtos inteligentes.

\section{ABSTRACT}

The present work aimed to explore the perception of key dimensions perceived by users of smart products that are: autonomy, ability to learn, reactivity, capacity for cooperation, human interaction and personality. For that, a qualitative research was carried out, through 15 interviews in depth using semi-structured questionnaire. NVivo ${ }^{\circledR}$ software was used for in-depth interview content analysis. Cluster analysis revealed the relationship between the dimensions of ability to cooperate and human interaction, as well as the dimension of autonomy with ability to learn. As main results, it can be affirmed that this work resulted in a greater understanding of the perception of the six key dimensions as well as their relation, frequency and importance for the users. In addition, three additional dimensions were identified: security, performance, and status; the status dimension being a result of the integrated perception of all other dimensions.

Keywords: Smart products. Smartphone. iPhone. Smart products key-dimensions. 


\section{INTRODUÇÃO}

A tecnologia da informação deu origem a uma nova geração de produtos que chegam ao mercado com tecnologia embarcada, são os chamados produtos inteligentes (KIRITSIS, 2011). Os produtos inteligentes são produtos que contém tecnologia da informação na forma de, por exemplo, microchips, softwares e sensores, portanto, são capazes de coletar, processar e produzir informações (RIJSDIJK; HULTINK; DIAMANTOPOULOS, 2007). O conceito abrange também os serviços e softwares que são capazes de se comunicar com outros produtos, dispositivos e usuários (AITENBICHLER et al., 2007; STÄNDER, 2010), dado que uma das características dos produtos inteligentes refere-se a sua capacidade de analisar informações e agir com base nas informações coletadas (RIJSDIJK; HULTINK, 2003).

Por isso, Lee (2014) afirma que os benefícios dos produtos inteligentes dependem da situação na qual são usados, mesmo assim, os produtos inteligentes são percebidos pelos usuários como melhores do que os não dotados de inteligência, já que são mais eficazes na resolução de problemas. Desta forma, os benefícios dos produtos inteligentes variam para diferentes ambientes, tais como: i) manufatura - melhoria no planejamento e controle da produção, aumento da eficiência para manufatura de produtos customizados, e redução de tempos de setup especialmente nas indústrias de placas de circuito impressas; ii) logística - redução no tempo de entrega, mudança de rota quando a carga já está em trânsito, segurança da rede de suprimento; iii) gerenciamento de bens - aumento da eficiência no compartilhamento, aproximação da localização do bem ao ponto de uso, agilidade na manutenção e reposição de itens; iv) gerenciamento do ciclo de vida de um produto - melhoria do design, manufatura, customização, manutenção e gerenciamento do fim da vida útil (MEYER; FRÄMLING; HOLMSTRÖM, 2009).

Os produtos inteligentes já são parte da realidade de pessoas em diferentes aplicações e contextos, tal como o TIVO, que é um produto desenvolvido pela Sony e Philips que analisa o comportamento do expectador, para posteriormente sugerir programas de televisão que possam ser de interesse do expectador (RIJSDIJK; HULTINK, 2003). Também, o cortador de grama solar da Husqvarna é capacitado para analisar a altura da grama e decidir de forma autônoma se a grama precisa ser cortada ou não, e consequentemente acionar a si mesmo (RIJSDIJK; HULTINK, 2003). Já o ToolWatch combina identificação e rastreamento o qual permitiu que a Bowen Engineering diminuísse os investimentos em ferramentas por meio de compartilhamento eficiente de ferramentas (MEYER; FRÄMLING; HOLMSTRÖM, 2009). Por sua vez, o Smart-IT é um dispositivo que pode ser acoplado a outros produtos e controlar os horários que os medicamentos de um paciente são ingeridos, além de contar quantas unidades de cada remédio estão disponiveis e se algum está vencido (MEYER; FRÄMLING; HOLMSTRÖM, 2009). Estas iniciativas focam no uso das TICs e na conexão entre todas as coisas, assim, além das pessoas estarem conectadas, 
os objetos também estão, para aprimorar e contribuir, significativamente, seja na vida ou trabalho das pessoas (MEIRELES; FEITOSA, 2019).

Dado os benefícios percebidos pelos produtos inteligentes, estudos foram realizados para entender melhor a relação entre usuários e produtos. Desta forma, o experimento realizado por Rijsdijk e Hultink (2003) questiona o quanto os consumidores apreciam a autonomia dos produtos inteligentes, e demonstra que o risco e a complexidade associados aos produtos são percebidos pelos consumidores de forma diretamente proporcional à sua autonomia. Mani e Chouk (2017) procuraram entender, por meio de surveys, quais os principais motivos percebidos por usuários para não utilizar produtos inteligentes, no caso desta pesquisa, o relógio inteligente. Os principais resultados mostraram que inutilidade percebida, preço percebido, grau de novidade percebido e preocupações quanto à privacidade são os fatores que afetam o uso de produtos inteligentes (MANI; CHOUK, 2017).

O iPhone foi escolhido como objeto para esta pesquisa dado que a Apple possui o segundo market share de smartphones, representando 15\% em todo mundo, sendo que em 2016 foram vendidos 211,88 milhões de aparelhos iPhone (STATISTA, 2017a). Atribui-se à venda dos aparelhos iPhone o valor da marca Apple no valor de 107,14 bilhões de dólares, ficando abaixo apenas da marca Google (STATISTA, 2017b). Pesquisas envolvendo o iPhone incluem a criação de aplicativos (CHRISTENSEN, 2009), a viabilidade do uso do iPhone para detectar fibrilação atrial e evitar derrames (LOWRES et al., 2014), análise forense por meio das redes sociais utilizadas em aparelhos iPhone (AL MUTAWA; BAGGILI; MARRINGTON, 2012) e caracterização dos consumidores digitais de aplicativos (KOOTI et al., 2017).

Levando em consideração o contexto atual dos produtos inteligentes, este artigo objetiva explorar as percepções dos usuários de iPhone quanto às dimensões-chave dos produtos inteligentes. Este estudo justifica-se pelo fato da crescente utilização e necessidade de produtos inteligentes, contudo há poucos estudos nesta área (MANI; CHOUK, 2017). Para tanto, este artigo está estruturado a partir desta introdução, seguida pela revisão da literatura dos produtos inteligentes tratando de sua definição e dimensões-chave. Posteriormente é apresentada a descrição do método utilizado, resultados encontrados e considerações finais.

\section{PRODUTOS INTELIGENTES}

\subsection{DEFINIÇÃO DE PRODUTOS INTELIGENTES}

Os produtos inteligentes são aqueles dotados de sensores, atuadores e conexão com redes (Wifi, Bluetooth ou RFID) e estão distribuidos em diversos segmentos, tais como saúde, casa, mobilidade e estilo 
de vida (PAPETTI et al., 2014). Objetos inteligentes (SO - Smart Objects), outra nomenclatura encontrada na literatura, diferenciam-se dos objetos comuns por serem dotados de sensores, memória e capacidade de comunicação, além de estarem imersos no ambiente, pondendo inclusive auxiliar usuários com deficiência física ou de idade avançada a viverem independentemente (PAPETTI et al., 2014).

Produtos inteligentes têm sido lançados no mercado, os quais são dispositivos de pequeno porte, como telefones celulares que mostram aumento no número de novos recursos e funções embarcados. Os produtos inteligentes distinguem-se de produtos tradicionais por sua capacidade de processar informações. Devido ao uso da tecnologia da informação, esses produtos operam de forma autônoma, cooperam com outros produtos ou se adaptam às circunstâncias em mudança (RIJSDIJK; HULTINK; DIAMANTOPOULOS, 2007).

De acordo com Rijsdijk e Hultink (2003), produtos inteligentes mostram pelo menos uma das seguintes características: i) capacidade de comunicação com outros produtos; ii) maior capacidade de processar informações torna os produtos mais flexíveis; iii) são decisores autônomos devido à sua capacidade de processar informações. Já para McFarlane et al. (2013), um produto inteligente possui cinco características: i) possui identificação única; ii) tem capacidade de comunicação eficaz com seu ambiente; iii) pode reter ou armazenar dados sobre si mesmo; iv) possui linguagem para exibir suas características, requisitos de produção, etc.; v) é capaz de participar ou tomar decisões relevantes para o seu próprio destino.

Já Leitão et al. (2015) defendem que um produto inteligente compreende Tecnologia da Informação (TI) na forma de software, microprocessadores e sensores, além de ser capaz de coletar e processar informações, gerando conhecimento, e até mesmo fornecendo recursos de raciocínio. Para a rastreabilidade e a identificação de produtos são usandas informações biométricas ou acrescenta-se instrumentos no produto com tecnologias relacionadas, como código de barras ou RFID (Radio Frequency Identifier). Dessa forma, cada produto inteligente fornece um conjunto de serviços relacionados ao produto, como monitoramento, análise de dados, autodiagnóstico e auto-manutenção.

Entretanto, Ventä(2007) refere-sea produtos inteligentes como aqueles que:i) possuemidentificação única; ii) são capazes de comunicar-se eficazmente com o ambiente; iii) podem reter ou armazenar dados sobre si mesmo; iv) implementam um idioma para exibir suas características e requisitos de produção; v) são capazes de participar ou tomar decisões relevantes para o seu próprio destino. Esta definição é focada em produtos orientados para a decisão, estendendo assim o ponto cinco da definição de McFarlane et al. (2013) e o ponto três da definição de Kärkkäinen et al. (2003). Por isso, a área de aplicação é a execução e manutenção de produtos em uso, com pouca ou nenhuma consideração de gerenciamento de fabricação 
e cadeia de suprimentos (MEYER; FRAMLING; HOLMSTROMC, 2009). Já para Maass e Varshney (2008), são seis as características presente nos produtos inteligentes:

a. personalização: customização dos produtos para atender as necessidades do cliente;

b. consciência comercial: preocupação com as restrições legais e comerciais;

c. capacidade de situar-se: reconhecimento dos contextos comunitários e situacionais;

d. adaptatividade: alterar o comportamento do produto de acordo com as reações do consumidor e as tarefas desenvolvidas;

e. habilidade de interação: habilidade de se comunicar e se agrupar com outros produtos;

f. pró-atividade: antecipar-se às intenções e planos do usuário.

Dadas as diferentes definições de produtos inteligentes apresentadas nesta seção, e levando em consideração as diferentes características propostas nos estudos abordados nesta subseção, percebe-se a necessidade de delimitar quais dimensões-chave dos produtos inteligentes serão utilizados para esta pesquisa. Dessa forma, as seis dimensões-chave propostas por Rijsdijk, Hultink e Diamantopoulos (2007) são detalhadas na próxima subseção.

\subsection{DIMENSÕES-CHAVE DOS PRODUTOS INTELIGENTES}

Este estudo adota as dimensões-chave que resultaram da pesquisa teórica e empírica de Rijsdijk, Hultink e Diamantopoulos (2007). Dessa forma, propõe-se a inteligência do produto consistindo em seis dimensões-chave: autonomia, capacidade de aprender, reatividade, capacidade de cooperação, interação humana (humanóide) e personalidade. Assim, a inteligência geral de um produto é conceituada pela medida que possui em cada uma dessas dimensões (RIJSDIJK; HULTINK; DIAMANTOPOULOS, 2007).

A autonomia do produto está relacionada a capacidade do produto entrar em ação sem intervenção humana (RIJSDIJK; HULTINK, 2003) e por isso interfere na sua funcionalidade, sendo que o mais alto nível de autonomia não depende de acionamento feito pelo ususário, podendo assim diminuir o valor emocional em relação ao produto (PARK; LEE, 2014). Desta forma, a autonomia ótima do produto deve levar em consideração o ponto no qual o usuário quer tomar as decisões (RIJSDIJK; HULTINK, 2003).

Entende-se que a autonomia de um produto pode ser classificada em quatro níveis: manual, limitada, supervisionada e simbiose (RIJSDIJK; HULTINK, 2003; BABER; 1996). A Figura 1 demonstra que a necessidade de intervenção humana é inversamente proporcional ao nível de autonomia do produto, ou seja, na medida que a necessidade de intervenção humana diminui, aumenta a necessidade de autonomia do produto. 
Figura 1 - Níveis de autonomia dos produtos

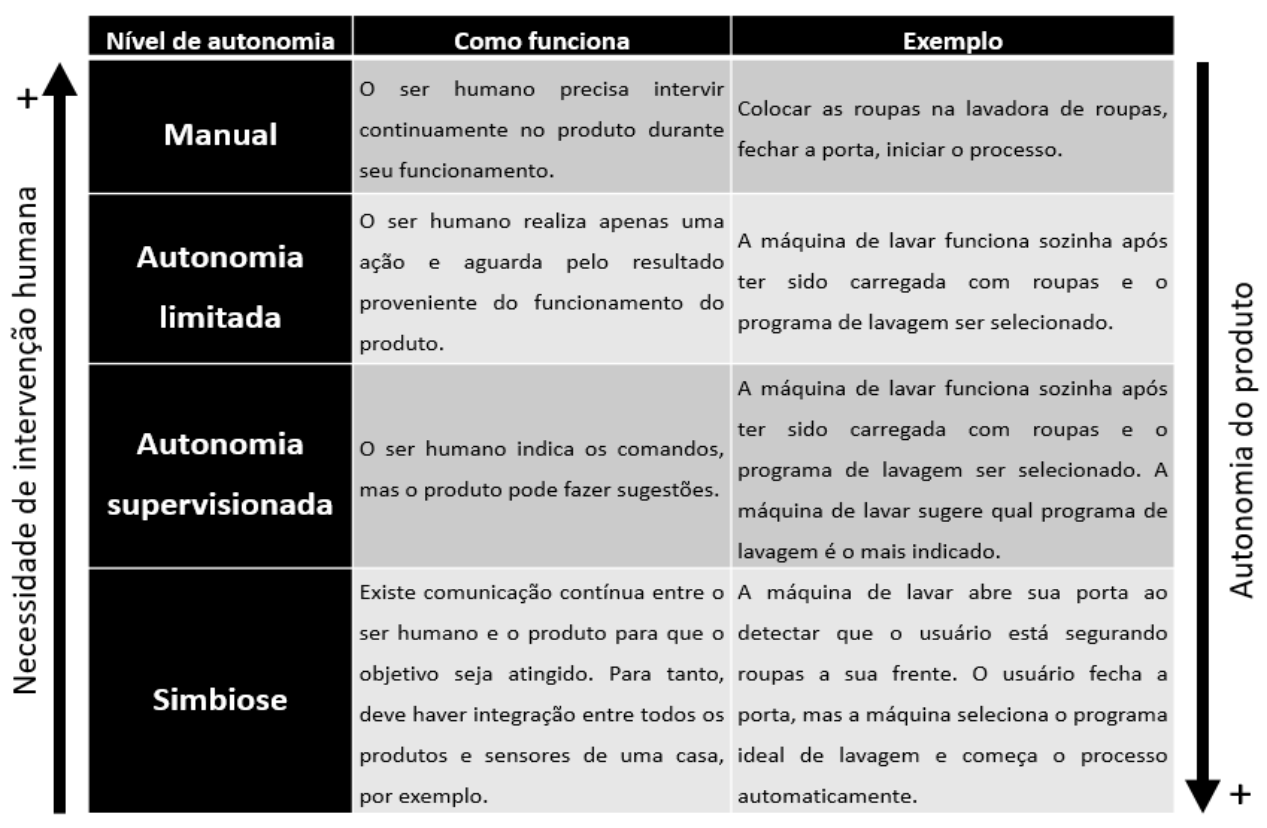

Fonte: Adaptada de (RIJSDIJK; HULTINK, 2003, p. 206; BABER; 1996, p.2).

A dimensão habilidade para aprender (ou adaptabilidade) confere aos produtos inteligentes a capacidade de armazenar dados do seu ambiente e reagir a estas informações. (RIJSDIJK; HULTINK; DIAMANTOPOULOS, 2007). Da mesma forma, Park e Lee (2014) consideram a habilidade para aprender como a adaptabilidade que o produto inteligente possui e que ao longo do tempo permite que o produto se adapte não somente às condições do ambiente, como também às necessidades do usuário. Para tanto, os softwares dos produtos inteligentes, considerados agentes deliberativos, constroem um modelo representativo a partir das informações coletadas do seu ambiente e do comportamento do usuário, e usam este modelo na tomada de decisões. Desta forma, um determinado produto inteligente poderá apresentar diferentes reações em diferentes ambientes (RIJSDIJK; HULTINK; DIAMANTOPOULOS, 2007).

A reatividade, assim como a habilidade para aprender, permite ao produto inteligente reagir às condições do ambiente externo, entretanto, o produto toma essa decisão baseado somente na condição atual do ambiente (RIJSDIJK; HULTINK; DIAMANTOPOULOS, 2007). Igualmente, Park e Lee (2014) consideram que a reatividade do produto se refere a sua habilidade em perceber o ambiente e reagir a ele. Destaca-se, nesta dimensão, o secador de cabelos Philips Hydraprotec, o qual ajusta a temperatura de acordo com a umidade do ar, mas sem memorizar estas informações para futuros usos (RIJSDIJK; 
HULTINK, 2009). Por isso, os produtos com níveis superiores de reatividade são percebidos como mais vantajosos (RIJSDIJK; HULTINK, 2009).

Da mesma forma que os produtos dotados de reatividade, os produtos dotados de habilidade para cooperar são percebidos como mais vantajosos e úteis (RIJSDIJK; HULTINK, 2009), uma vez que a dimensão-chave habilidade para cooperar refere-se a capacidade de união dos produtos inteligentes de forma a atingir um objetivo comum, sendo que essa habilidade já existe em computadores e seus periféricos (RIJSDIJK; HULTINK; DIAMANTOPOULOS, 2007), ou no caso dos celulares que podem ser usados como modem para um computador (PARK; LEE, 2014). A partir disso, entende-se que existe tendência de que os produtos que funcionam de forma isolada são mais propensos a desaparecer, já que novos produtos lançados no mercado possuem a capacidade de interação com o usuário e com outros aparelhos (RIJSDIJK; HULTINK, 2009).

A dimensão interação humana trata do nível de capacidade que os produtos inteligentes possuem para comunicarem-se com os usuários de forma natural e semelhante ao discurso humano (RIJSDIJK; HULTINK, 2009), a exemplos dos dispositivos de GPS (Global Positioning System) que guiam os usuários por meio de voz, podendo também ser acionados por comando de voz (RIJSDIJK; HULTINK; DIAMANTOPOULOS, 2007). Alerta-se para a possibilidade da dependência que o consumidor pode apresentar em relação a um produto inteligente com capacidade de interação humana, pois existe uma tendência, ao longo do tempo, de associar o software ou aplicativo com função de assistente pessoal a um amigo pessoal (PARK; LEE, 2014).

A sexta dimensão é chamada de personalidade, pois classifica a capacidade do produto inteligente de demonstrar personalidade e estado emocional de forma convincente para o usuário (RIJSDIJK; HULTINK; DIAMANTOPOULOS, 2007). Desta forma, a comunicação entre agentes autonômos interagindo com seres humanos, identificou que o feedback envelope, ou seja, o feedback que diz respeito aos aspectos externos da comunicação, e não ao conteúdo, é mais importante para comunicação, e tem um papel essencial para o diálogo, além de aumentar a fluidez das interações entre agentes humanóides e seres humanos (CASSELL; THORISSON, 1999). Com o objetvo de facilitar entendimento, o Quadro 1 apresenta um resumo das seis dimensões abordadas. 
Quadro 1 - Resumo das dimensões

\begin{tabular}{|c|c|c|}
\hline Dimensão analisada & Caracterização da dimensão & Autores \\
\hline Autonomia & $\begin{array}{l}\text { A autonomia do produto está relacionada a capacidade do produto } \\
\text { entrar em ação sem intervenção humana, com pouca intervenção } \\
\text { humana ou com constante intervenção humana. }\end{array}$ & $\begin{array}{l}\text { Rijsdijk e Hultink (2003) } \\
\text { Park e Lee (2014) }\end{array}$ \\
\hline $\begin{array}{l}\text { Habilidade } \\
\text { para aprender } \\
\text { (adaptabilidade) }\end{array}$ & $\begin{array}{l}\text { Considera-se a habilidade para aprender como a adaptabilidade } \\
\text { que o produto inteligente possui e que ao longo do tempo permite } \\
\text { que o produto se adapte não somente as condições do ambiente, } \\
\text { como também as necessidades do usuário. }\end{array}$ & $\begin{array}{l}\text { Rijsdijk, Hultink e } \\
\text { Diamantopoulos (2007) }\end{array}$ \\
\hline Reatividade & $\begin{array}{l}\text { Permite ao produto reagir às condições do ambiente externo, } \\
\text { entretanto o produto toma essa decisão baseado somente na } \\
\text { condição atual do ambiente. Refere-se a habilidade em perceber o } \\
\text { ambiente e reagir a ele. }\end{array}$ & $\begin{array}{l}\text { Rijsdijk, Hultink e } \\
\text { Diamantopoulos (2007) } \\
\text { Park e Lee (2014) }\end{array}$ \\
\hline $\begin{array}{l}\text { Habilidade para } \\
\text { cooperar }\end{array}$ & $\begin{array}{l}\text { Refere-se a capacidade de união dos produtos inteligentes de } \\
\text { forma a atingir um objetivo comum, habilidade já existente em } \\
\text { computadores e seus periféricos e em celulares. }\end{array}$ & $\begin{array}{l}\text { Rijsdijk, Hultink e } \\
\text { Diamantopoulos (2007) } \\
\text { Park e Lee (2014) }\end{array}$ \\
\hline $\begin{array}{c}\text { Interação humana } \\
\text { (humanlike interaction) }\end{array}$ & $\begin{array}{l}\text { A dimensão de interação humana trata do nível da capacidade } \\
\text { que os produtos inteligentes possuem para comunicarem-se com } \\
\text { os usuários de forma natural e semelhante ao discurso humano. } \\
\text { Perceber a assiste pessoal de um celular como um amigo. }\end{array}$ & $\begin{array}{l}\text { Rijsdijk e Hultink (2009) } \\
\text { Rijsdijk, Hultink e } \\
\text { Diamantopoulos (2007) }\end{array}$ \\
\hline Personalidade & $\begin{array}{l}\text { A dimensão da personalidade classifica a capacidade do produto } \\
\text { inteligente de demonstrar personalidade e estado emocional de } \\
\text { forma convincente para o usuário. Fluidez das interações entre } \\
\text { agentes humanoides e seres humanos. }\end{array}$ & $\begin{array}{l}\text { Rijsdijk, Hultink e } \\
\text { Diamantopoulos (2007) } \\
\text { Cassell; Thorisson, (1999) }\end{array}$ \\
\hline
\end{tabular}

Fonte: Elaborada pelos autores (2017).

\section{MÉTODO}

Esta pesquisa, do ponto de vista de sua natureza, trata de uma pesquisa aplicada, com abordagem qualitativa (FLICK, 2009; CRESWEL, 2013) e caráter exploratório (CRESWEL, 2013) dado que busca entendimento quanto a percepção dos usuários sobre produtos inteligentes. Para tanto, a técnica de coleta de foi a de entrevistas semiestruturada com roteiro básico de questões, desta forma foram realizadas entrevistas pessoais em profundidade (BAUER; GASKEL, 2000; EISENHARDT; GRAEBNER, 2007), as quais foram posteriormente transcritas e preparadas para a análise.

O questionário semiestruturado foielaborado a partir do trabalho de Rijsdijk; Hultinke Diamantopoulos (2007), levando em consideração as dimensões-chave: autonomia, capacidade de aprender, reatividade, capacidade de cooperação, interação humana e personalidade. O motivo para escolha de entrevista 
semiestruturada refere-se ao fato desta buscar compreender os significados que os entrevistados relacionam às questões e situações que são de interesse do pesquisador, assim como de qual forma os entrevistados fundamentam suas opiniões (MALHOTRA, 2005). O roteiro semiestruturado utilizado foi validado por dois experts e foi aplicado após atender as alterações sugeridas. As seis dimensões-chave foram utilizadas para definição das categorias de análise à priori de conteúdo (BAUER; GASKEL, 2000; BARDIN, 2006; FLICK, 2009). A próxima seção apresenta os resultados encontrados a partir da coleta e análise de dados.

A análise das entrevistas ocorreu por meio de análise de conteúdo (BAUER; GASKEL, 2000; BARDIN, 2006; FLICK, 2009), a qual foi realizada com auxílio do software Nvivo ${ }^{\circledR}$ versão 11. A matriz de codificação no NVivo ${ }^{\circledR}$ possibilita, por exemplo, análises e explorações das codificações realizadas em diversos temas ou temas e perfis de respondentes (atributos de casos) de forma cruzada, auxiliando a procura de sobreposições e interseções entre elas. Tais codificações constituem-se na reunião de todo o material sobre um tema, ideia ou tópico. Assim, as consultas às matrizes de codificação permitem comparações entre o material codificado para mostrar tipos específicos de associações entre itens de pesquisa (MOZZATO; GRZYBOVSKI; TEIXEIRA, 2016). Para esta pesquisa foram consideradas as seguintes etapas para a análise com auxílio do NVivo ${ }^{\circledR}$ : (i) divisão dos dados e atribuição de códigos para palavras-chave ou trechos; (ii) fazer anotações sobre os dados para dar significado a eles; (iii) mapeamento de relações entre as transcrições e os códigos; (iv) buscas de palavras e conjunto de palavras específicas.

Os entrevistados foram escolhidos a partir do uso do produto inteligente pesquisado, iPhone, o qual contemplava as dimensões indentificadas à priori pela literatura. Na próxima seção apresentam-se os dados coletados, as análises realizadas e apresentação dos resultados.

\section{ANÁLISE DOS RESULTADOS}

As 15 entrevistas pessoais aconteceram em julho de 2017, com duração média de 25 minutos e 38 segundos. Foram entrevistados 5 mulheres e 10 homens, com idades variando entre 19 e 56 anos e média 28,33. Quanto ao uso do produto, a maioria (12 entrevistados) afirma usar o produto para trabalho e lazer. 0 tempo de uso do produto varia entre 5 meses e 120 meses, sendo a média de uso de 54 meses. O nível de escolaridade dos entrevistados varia entre ensino médio incompleto até doutorado completo. Os níveis de renda variam de até um salário mínimo até mais de sete salários mínimos mensal individual. O Quadro 2 apresenta o perfil dos entrevistados. 


\begin{tabular}{|c|c|c|c|c|c|c|c|c|}
\hline Ordem & $\begin{array}{l}\text { Tempo de } \\
\text { entrevista }\end{array}$ & Sexo & Idade & $\begin{array}{l}\text { Uso do } \\
\text { Produto }\end{array}$ & $\begin{array}{c}\text { Tempo } \\
\text { de uso do } \\
\text { produto }\end{array}$ & $\begin{array}{l}\text { Escola- } \\
\text { ridade }\end{array}$ & $\begin{array}{l}\text { *Renda Mensal } \\
\text { Individual }\end{array}$ & Ocupação \\
\hline 1 & $22: 34$ & M & 24 & $\begin{array}{l}\text { Lazer e } \\
\text { Trabalho }\end{array}$ & 8 anos & Sup. Inc. & Até 1 & Professor \\
\hline 2 & $15: 57$ & $F$ & 18 & $\begin{array}{l}\text { Lazer e } \\
\text { Trabalho }\end{array}$ & $\begin{array}{c}1 \text { ano e } 6 \\
\text { meses }\end{array}$ & $\begin{array}{l}\text { Médio } \\
\text { Compl. }\end{array}$ & Até 1 & Professora \\
\hline 3 & $22: 41$ & M & 29 & $\begin{array}{c}\text { Comunicação } \\
\text { em geral }\end{array}$ & 1 ano & Mestr. Inc. & Entre 1 e 2 & $\begin{array}{c}\text { Bolsista de } \\
\text { pesquisa }\end{array}$ \\
\hline 4 & $14: 37$ & M & 32 & $\begin{array}{l}\text { Lazer e } \\
\text { Trabalho }\end{array}$ & 3 anos & Sup. Inc. & Entre 3 e 4 & $\begin{array}{l}\text { Analista de } \\
\text { engenharia }\end{array}$ \\
\hline 5 & 42:35 & M & 31 & $\begin{array}{l}\text { Lazer e } \\
\text { Trabalho } \\
\end{array}$ & $\begin{array}{c}1 \text { ano e } 3 \\
\text { meses }\end{array}$ & Esp. Compl. & Entre 3 e 4 & $\begin{array}{l}\text { Analista da } \\
\text { qualidade }\end{array}$ \\
\hline 6 & $20: 31$ & M & 20 & $\begin{array}{l}\text { Lazer e } \\
\text { Trabalho }\end{array}$ & 2 anos & $\begin{array}{l}\text { Médio } \\
\text { Compl. }\end{array}$ & Entre 2 e 3 & $\begin{array}{c}\text { Coordenador } \\
\text { pedagógico }\end{array}$ \\
\hline 7 & 31:00 & M & 32 & $\begin{array}{c}\text { Lazer, } \\
\text { Trabalho e } \\
\text { Compras }\end{array}$ & 3 anos & $\begin{array}{l}\text { Superior } \\
\text { Inc. }\end{array}$ & Entre 1 e 2 & Professor \\
\hline 8 & 20:18 & $F$ & 21 & $\begin{array}{l}\text { Lazer e } \\
\text { Trabalho }\end{array}$ & $\begin{array}{c}2 \text { anos e } 6 \\
\text { meses }\end{array}$ & Mestr. Inc. & Entre 1 e 2 & $\begin{array}{c}\text { Bolsista de } \\
\text { pesquisa }\end{array}$ \\
\hline 9 & $19: 50$ & $F$ & 28 & $\begin{array}{l}\text { Lazer e } \\
\text { Trabalho }\end{array}$ & 3 anos & $\begin{array}{l}\text { Mestr. } \\
\text { Compl. }\end{array}$ & Entre 4 e 5 & $\begin{array}{c}\text { Técnica de } \\
\text { saneamento }\end{array}$ \\
\hline 10 & $14: 23$ & M & 19 & Lazer & 1 ano & $\begin{array}{c}\text { Médio-Téc. } \\
\text { Inc. }\end{array}$ & Até 1 & Estagiario \\
\hline 11 & 31:02 & M & 31 & $\begin{array}{l}\text { Lazer e } \\
\text { Trabalho }\end{array}$ & 5 anos & Sup. Inc. & Mais de 7 & $\begin{array}{c}\text { Supervisor de } \\
\text { Produção }\end{array}$ \\
\hline 12 & $38: 56$ & M & 28 & $\begin{array}{l}\text { Lazer e } \\
\text { Trabalho }\end{array}$ & 7 anos & Sup.Compl. & Entre 4 e 5 & $\begin{array}{c}\text { Analista de } \\
\text { Sistema }\end{array}$ \\
\hline 13 & 29:51 & $F$ & 29 & $\begin{array}{l}\text { Lazer e } \\
\text { Trabalho }\end{array}$ & 6 anos & $\begin{array}{l}\text { Dout. } \\
\text { Compl. }\end{array}$ & Entre 2 e 3 & Professor \\
\hline 14 & $38: 16$ & $F$ & 27 & $\begin{array}{l}\text { Lazer e } \\
\text { Trabalho }\end{array}$ & 5 meses & Dout. Inc. & Até 1 & Estudante \\
\hline 15 & $22: 12$ & M & 56 & $\begin{array}{l}\text { Lazer e } \\
\text { Trabalho }\end{array}$ & 10 anos & $\begin{array}{l}\text { Dout. } \\
\text { Compl. }\end{array}$ & Mais de 7 & Coordenador \\
\hline
\end{tabular}

${ }^{*}$ Renda Mensal Individual em salários mínimos ( $\left.\$ \$ 937,00\right)$.

Fonte: Elaborado pelos autores de acordo com as entrevistas (2017). 
As categorias definidas à priori para análise de conteúdo permitiram identificar as percepções dos usuários quanto as dimensões-chave autonomia, habilidade para aprender, reatividade, habilidade para cooperar, interação humana (humanóide) e personalidade. A codificação foi realizada manualmente e também com auxílio do software Nvivo Plus, ocorrendo posteriormente a comparação. O Quadro 3 exibe as referências e fontes para as categorias estabelecidas à priori. Neste quadro a coluna fonte representa a quantidade de entrevistados que mencionaram a dimensão. A coluna referências quantifica o número de vezes que a respectiva dimensão foi citada nas entrevistas. Nesta perspectiva, a dimensão interação humana foi a mais citada pelos usuários entrevistados, sendo referenciada 135 vezes suportando a sua importância nos produtos inteligentes. Vale ressaltar que este achado difere da pesquisa empírica de Rijsdijk e Hultink (2007) que encontrou média $(3,74)$ para a dimensão interação humana, a menor entre as seis dimensões estudadas. Isto pode ser explicado pela complexidade de medir esta dimesão quantitavivamente, ou seja, a profundidade da pesquisa qualitativa permite que a interação humana seja melhor compreendida e valorizada.

Quadro 3 - Referências e fontes a partir da análise de conteúdo

\begin{tabular}{|l|c|c|}
\hline \multicolumn{1}{|c|}{ Dimensão-chave } & Referências & Fontes \\
\hline Autonomia & 112 & 15 \\
\hline Habilidade para aprender & 119 & 15 \\
\hline Reatividade & 98 & 15 \\
\hline Habilidade para cooperar & 110 & 15 \\
\hline Interação humana & 135 & 15 \\
\hline Personalidade & 89 & 15 \\
\hline
\end{tabular}

Fonte: Elaborado pelos autores com base no software NVivo ${ }^{\circledR}$ (2017).

Quanto à dimensão autonomia pode-se afirmar que os respondentes entendem que o iPhone tem capacidades de autonomia variada: desde autonomia sem intervenção humana até constante intervenção humana. A autonomia, de uma forma geral, é percebida como positiva, dado que a maioria das ações solicita permissão para progredir, ou demanda configuração prévia. Quando a configuração prévia permite que o telefone não exija autorização para algumas tarefas, os respondentes perceberam maior nível de autonomia associado ao iPhone. O Quadro 4 resume as principais funções associadas a autonomia do iPhone. Além disso, os entrevistados destacaram a importância de decidir quem é o tomador de decisões para as atividades do iPhone: 
Porque o mais importante é ele funcionar quando eu quero, na hora que eu quero (Entrevistado 4).

Não creio que toma decisões, mas ele vai me auxiliar com as informações e o conhecimento que ele pode me atribuir e com isso eu vou tomar as decisões (Entrevistado 13).

Ele mostra o que precisa ser feito, mas ele depende do meu comando para autorizar ou não, neste sentido eu discordo um pouco. Ele é muito mais, demonstra o que precisa, o que daria para fazer, mas ele sempre depende do teu ok, o que para mim é bom (Entrevistado 14).

Quanto à dimensão-chave habilidade para aprender, os respondentes identificaram Inteligência Artificial (Al), algoritmos inteligentes e avançados como responsáveis pela habilidade que o iPhone possui de aprender e conhecer o perfil do usuário e adaptar-se a ele, personalizando e tornando customizada a utilização, consequentemente facilitando a adaptabilidade do iPhone ao usuário e vice-versa. A forte relação encontrada aqui da dimensão habilidade de aprender com a inteligência do produto é corroborada pelos achados de Rijsdijk e Hultink (2007).

Eu acho que com algoritmos, cada vez que eu uso ele manda um sinal, alguma coisa assim (Entrevistado 10).

A partir do momento que tu começas a usar ele, ele começa a agilizar, ele vai conhecendo o teu perfil e vai antecipando algumas coisas que tu buscas nele, desde a preferência por ligações, preferencias por músicas, tempo, agenda, então, ele identifica o usuário e se adapta ao usuário. Eu acredito que é um algoritmo inteligente que ele tem, um algoritmo avançado que faz leituras do usuário e vai de certa forma conhecendo cada perfil, ele tem no seu código fonte (Entrevistado 11).

Então eu acho que tudo isso são algoritmos. Eles vão vendo que tu ta clicando e automaticamente aprende mas não é uma coisa automática, é porque de alguma forma ele é habilitado para isso (Entrevistado 9). 
Quadro 4 - Funções percebidas pelos entrevistados na dimensão-chave autonomia

\begin{tabular}{|c|c|}
\hline Função & Entrevistados \\
\hline Solicitar permissão para atualizar & $1,4,5,6,8,9,10,13,14$ \\
\hline Conectar automaticamente ao Wifi em redes conhecidas. & $1,2,3,7$ \\
\hline Alterar brilho da tela conforme luz do ambiente & $1,6,7,10$ \\
\hline Organização do tempo e atividades por meio da agenda e lembretes & $11,12,13,15$ \\
\hline Sugerir ativação do modo de economia de bateria & $1,2,6,9$ \\
\hline Atualizar software automaticamente & $4,5,8,12$ \\
\hline Sugerir liberação de espaço de memória & $1,6,12$ \\
\hline Abrir aplicativo iTunes automaticamente ao se conectar com outro dispositivo (carro ou computador, por exemplo) & $2,4,6$ \\
\hline Sincronizar iTunes ao conectar o iPhone no computador & 2,5 \\
\hline Gerenciamento de fotos & 7,11 \\
\hline Religar automaticamente & 10,14 \\
\hline Auxilia na tomada de decisão & 11,13 \\
\hline Traçar rotas para locais pesquisados & 11,13 \\
\hline Solicitar permissão para acesso a localização & 14,15 \\
\hline Conectar ao Bluetooth do carro & 4,6 \\
\hline Gerenciar armazenamento de arquivos na memória física e na nuvem & 7,8 \\
\hline Ativar o uso do flash na câmera fotográfica & 1 \\
\hline Solicitar permissão para Limpeza inteligente e backup & 5 \\
\hline Enviar e-mails para o lixo eletrônico & 5 \\
\hline Conectar à televisão smart & 5 \\
\hline Troca de informação entre aplicativos & 7 \\
\hline Edição automática de fotos (tratamento) & 7 \\
\hline Bloquear após um tempo programado sem uso & 7 \\
\hline Ajustar relógio (horário de verão e fusos horários) & 9 \\
\hline Completar frases ou palavras & 10 \\
\hline Sugestão de músicas & 11 \\
\hline Automatização de senhas & 11 \\
\hline Traçar rotas melhores & 12 \\
\hline Troca de informação entre outros dispositivos Apple & 12 \\
\hline Abrir o aplicativo necessário para exibir os links recebidos & 14 \\
\hline Solicitar permissão para acesso ao microfone e câmera & 14 e 15 \\
\hline
\end{tabular}

Fonte: Elaborado pelos autores com base nas entrevistas (2017). 
Outro ponto destacado nas entrevistas é que as atualizações nos softwares ou aplicativos são percebidos como melhoria de desempenho e adicionam funções facilitadoras da interatividade. Alguns respondentes até quantificaram como sendo necessário repetir uma determinada interação com o iPhone três vezes para que seja mapeado o perfil do usuário, como por exemplo, nas sugestões feitas pelo teclado.

No inicio eu precisava mostrar para o telefone que eu queria escrever errado intencionalmente. Mas isso acontece com uma palavra por umas 3 vezes no máximo, depois ele já aprende o que tem que fazer (Entrevistado 1).

Às vezes se ele esta conectado no carro na hora que eu ligo o carro ele já me diz que falta tantos minutos para chegar em tal lugar e eu nunca mexi com isso, nunca programei para esse tipo de coisa. Acho que os mapas as coisas assim devem aprender sozinhos os lugares que a gente mais transita ou circula (Entrevistado 1).

Quanto à melhoria do desempenho do aparelho, as opiniões se dividem. Os usuários citam a incapacidade de atualização de software nos aparelhos e as restrições de bateria como limitações a melhoria de desempenho do aparelho.

Olha só, eu acho que ele vai ficar pior no usar. Eles têm uma politica de fechar o sistema deles, então tem alguns aplicativos, que eu não consigo mais baixar, aqui entendeu. Eu acho que é o aspecto ruim dele. Dessa marca aqui. Então chega num momento, eu não consigo baixar outros aplicativos, tipo Uber, eu não consigo. Ele fala que teu software tem que atualizar, mas só que ele não vai. É que ele, ele não atualiza mais. Ele já chegou no limite dele (Entrevistado 3).

Por causa da obsolescência programada do iPhone ele fica inútil muito rápido então, por exemplo, no primeiro ano que tu tem ele é o melhor celular que tu pode ter, depois disso ele começa a ficar devagar, devagar, devagar, e hoje por exemplos estou tendo problemas com minha bateria (Entrevistado 10).

A própria questão da melhoria contínua por atualizações de aplicativos que constantemente eles solicitam pra que o aparelho tenha melhor desempenho, rapidez, e que faz com que ele seja sempre atualizado pra novamente me auxiliar, com informações novas e com a funcionalidade de cada aplicativo e de todos os programas que ele possui (Entrevistado 13). 
Ao questionar os usuários de iPhone quanto à dimensão-chave reatividade, os conteúdos das respostas convergiram no sentido de que o aparelho reage a condições do ambiente externo e esta capacidade está relacionada com a configurações previamente ajustadas.

Tem decisões simples, por exemplo como ajustar o brilho, no sol ele ajusta o brilho sozinho, questões de bateria, ele tem diferentes picos na bateria, abaixo de 15\% mesmo que tu não acione para poupar bateria ele começa a poupar. Ele reduz o volume em contato com a superfície (Entrevistado 6).

Eu percebo que ele alterava o brilho da tela, mas eu desabilitei, por exemplo, o da tela (Entrevistado 7).

Nota-se que usuários que utilizam o iPhone como ferramenta de trabalho, por exemplo para gestão de ordens de serviço: abertura, status, feedback, controle, etc., percebem mais efetivamente a dimensão da reatividade, pois as configurações do smartphone são definidas com propósitos de gestão de projetos. Logo, essa configuração business é com propósitos de planejamento e controle:

A abertura e fechamento das minhas ordens de serviço todas funcionam ali (no celular); é uma forma da empresa ver se eu estou realmente trabalhando ou não. As rotas de minhas viagens para meus clientes são monitoradas para prestação de contas dos meus gastos, então todo o meu trajeto eu envio para a empresa; para enviar o trajeto eu uso o Waze. O Waze para mim é o melhor, monitora todo o trânsito, também é uma forma de monitorar os outros usuários para ver como está o trânsito para minha melhor performance, assim como dos outros usuários ou avisos de buracos, enfim. É uma forma de estar de olho em mim em todo ambiente. O celular monitora, é uma forma de a empresa estar de olho em mim, e ver se eu estou realmente nos ambientes que eu devia estar (Entrevistado 12).

A habilidade de cooperação é percebida com valor por parte dos respondentes, pois expande funções e potencializa a conectividade do próprio iPhone, este achado diverge da pesquisa empírica realizada por Lee e Shin (2018) que ao contrário identificou baixa relação esta dimensão e inteligência de produto. 0 resultado da interação é melhor comparado ao iPhone isolado, ou seja, opera melhor em conexão com outros dispositivos. Por meio da análise de conteúdo das respostas, sugere-se que o iPhone precisa de outros aparelhos ou dispositivos (outros iPhones, tablets, computadores, TV, rádio do carro, nuvem, etc.) para se complementar, ou seja, remete-se a ideia de família de produtos em cooperação. 
Ele facilita tua vida no sentido que não tem que pegar ele na mão, não tem que ir até o aplicativo de músicas e escolher uma música. Então, ele agiliza processo, em geral. Na minha opinião, são todas coisas que tu poderia fazer, ir lá escolher tua música, sincronizar e sair dirigindo. Mas ele facilita, ele torna mais confortável, ele elimina partes do processo, torna ele mais ágil (Entrevistado 6).

Escutar música no carro, usar como por exemplo, o celular está sempre na minha mão, então da mesma maneira que eu acesso e-mail eu posso mudar de canal na tv ou aumentar o volume da tv sem....ele traz praticidade, otimiza meu tempo, e elimina cabos (Entrevistado 7).

Quando a utilização do iPhone tem foco no ambiente de negócios, a cooperação acaba sendo incorporada no processo. Por exemplo, conforme argumentação de um usuário, o iPhone auxilia no desenvolvimento do sistema de ERP da empresa o que está auxiliando a empresa na tomada de decisões mais rápida.

No ramo aonde eu trabalho, a gente usa agenda das atividades; a gerente de projeto programa as atividades e eles acabam disparando na minha agenda visita a clientes, o que eu vou fazer, as execuções, assim como quando eu encerro minhas atividades, por meio do computador ou celular e envio (feedback) para a gerente de projetos (Entrevistado 12).

A habilidade de cooperação do iPhone também é valorizada pelos entrevistados levando em consideração as configurações e arquivos de usuário em diferentes produtos da marca Apple:

Se for relacionar com produtos Apple é nativo, ele se comunica de uma forma extremamente simples, sem praticamente nenhuma configuração. As opções são já disponibilizadas na tela e este produto se comunica com os demais de uma forma extremamente simples e fácil sem necessidade de programação ou de configuração; a comunicação é nativa e extremamente intuitiva. Então a gente se conecta extremamente rápido e fácil com outros dispositivos (Entrevistado 15).

No momento que você compra o celular, você liga ele e faz um cadastramento, tu vais informar todos os teus dados pessoais e o teu email que é a conta que tu usas normalmente. No momento que você compra outro aparelho, você vai utilizar o mesmo cadastro e a partir disso vai gerar interação entre um e outro, os aparelhos vão se identificar observando que é a mesma pessoa que utiliza, então até os próprios aplicativos são instalados em ambos aparelhos iPhone e iPad. Ele percebe que tu és a mesma pessoa e que tu vais estar utilizando provavelmente as mesmas informações 
com outros aplicativos, muitas vezes informações são capatadas no iPhone e tu vais utilizar no Mac (Entrevistado 12).

A assistente pessoal do iPhone é evidenciada pelos respondentes como principal canal de comunicação homem-máquina, com características humanóides. A comunicação pode ser realizada por meio de diálogo, no caso da Siri, a qual utiliza inteligência artificial para proporcionar alternativas, com base nas necessidades explícitas, e por vezes implícita, dos usuários. A Figura 2 mostra a nuvem de palavras geradas para a dimensão interação humana. O cluster de palavras (Figura 2) é uma ferramenta que indica a relação textual de acordo com a análise dos trechos codificados, entre os objetivos propostos e os resultados encontrados, neste caso especificamente gereda para a dimensão interação humana. Por exemplo, a nuvem de palavras traduz uma relação muito estreita entre a "Siri" e "fazer", denotando papel proativo da inteligência artificial do smartphone a serviço o usuário.

Figura 2 - Nuvem de palavras da dimensão interação humana

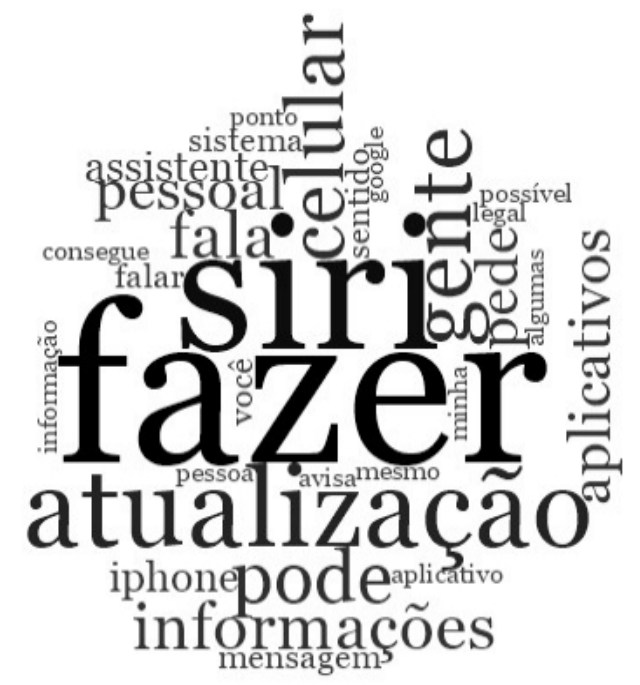

Fonte: Elaborado pelos autores por meio do software NVivo ${ }^{\circledR}$ (2017).

O iPhone proporciona feedback buscando os melhores resultados com base no perfil e dados de entrada do usuário, por vezes, a interação é desenvolvida divertidamente. A dimensão de interação humana foi a mais citada em todas as entrevistas, já que na maioria das ações executadas pelo celular acontecem pequenos diálogos, nos quais o aparelho solicita confirmação ou ação por parte do usuário. Este achado também foi evidenciado pela pesquisa empírica de Lee e Shin (2018), aonde a equivalente dimensão multifuncionalidade teve forte relação com a inteligência do produto. 
As explicações são poucas e de certa forma desnecessárias em grande parte, porque a utilização do aparelho é quase que intuitiva. Então existe uma inteligência a tal ponto no aparelho que as regras não precisam ser claras, as instruções não precisam ser precisas, ele faz interpretações do que se quer de uma forma mais subjetiva. É mais intuitivo o uso do aparelho do que propriamente um manual de regras de como utilizar (Entrevistado 15).

Eu acho que é possivel dialogar com qualquer máquina que te conecte com a internet. Fazer uma pergunta é semelhante a tu fazer uma pergunta no Google. E tu ouvir uma resposta é semelhante a tu ler um texto. Então eu acho que sim, mas eu acho que tu não está dialogando com a máquina, mas serve como uma ferramenta para um outro diálogo (Entrevistado 6).

Ela responde, ela é bem inteligente para responder. Bem convicente, para um aparelho (Entrevistado 8).

Os respondentes têm percepções bastante distintas em relação a dimensão personalidade. Alguns respondentes demonstraram perceber personalidade, semelhanças cognitivas e emocionais no iPhone parecidas com os seres humanos. Atribui-se estas diferenças ao nível de envolvimento e customizações na utilização do iPhone. Os respondentes compararam o celular a uma pessoa muito comunicativa, que realmente gosta de falar. As pessoas declaram uma ligação emocional com o iPhone, pois estão sempre atreladas a ele.

Quando eu penso no iPhone, me vem na cabeça pessoas ricas, pessoas conectadas, chiques e atualizadas (Entrevistado 1).

A principal propriedade que eu vejo semelhante de um ser humano é o poder de tomada de decisão, ele analisa e te devolve uma decisão, que como usuário vai te ajudar em algum momento; seja na parte de assistente pessoal ou na geolocalização para chegar mais rápido em um local. Então dá para se comparar com uma inteligência humana (Entrevistado 11).

Uma característica parecida com seres humanos é a organização. Quando um software é lançado ele tem que suprir algumas características, pois você quer ganhar tempo em outros momentos. 0 celular vem para suprir em algumas características em alguns momentos, organizar, alinhar; características que as vezes você mesmo não tem, as vezes você não é organizado. Então o teu celular tem uma característica humana de se organizar e aí te determinar as atividades (Entrevistado 12). 
Também dá para fazer a seguinte analogia, como se fosse um bebê e uma mãe, a mãe vai ter que ficar o dia todo cuidando aquela criança, e hoje as pessoas tem comportamento de estar sempre conectadas, sempre com o celular verificando mensagens; é como se fosse mãe e um filho; dá sim pra fazer uma metáfora de mãe e bebê porque as pessoas estão sempre atreladas a ele (Entrevistado 13).

Algumas situações sim. A Siri tem propriedades de humor, por exemplo de ironia. Então, sim, o aparelho já começa a ter características humanas. Humor, ironia, sarcasmo em algumas situações. Algumas questões de tratamento, de humano para outro humano o sistema já começa a entender. A questão de ajuda, a forma de interagir, agradecendo, pedindo. Algumas carcterísticas de empatia começam a ser embutidas nesta inteligência (Entrevistado 15).

Durante as entrevistas e análises surgiram alguns pontos que merecem ser mencionados. A Figura 3 representa uma análise de cluster, a qual relaciona as seis dimensões propostas por Rijsdijk, Hultink e Diamantopoulos (2007). Além destas dimensões, a análise de conteúdo das entrevistas identificou mais três dimensões: segurança, desempenho e status.

Figura 3 - Relacionamento entre as dimensões

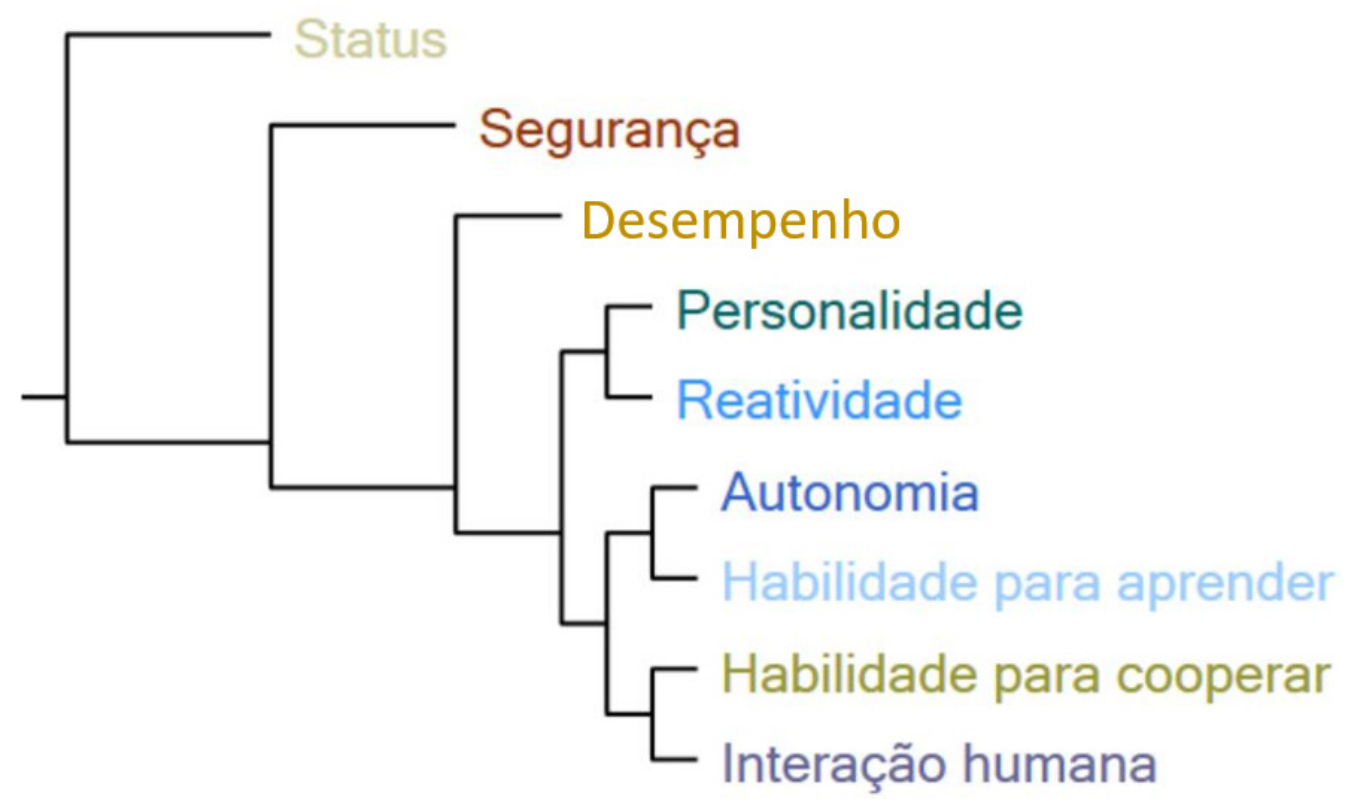

Fonte: Elaborado pelos autores a partir do software NVivo ${ }^{\circledR}$ (2017). 
Dos 15 entrevistados, 7 destacaram a importância da segurança para decisão de compra do aparelho, como evidenciado a seguir. Este achado corrobora Meireles e Feitosa (2019), que destacam a segurança dos dados como dimensão de análise a ser desenvolvida nas cidades inteligentes, as quais são compostas por inúmeros produtos inteligentes. A dimensão segurança também é sustentada pela pesquisa de Werner, Frazzon e Forcelini (2019) em produtos inteligentes no contexto hospitalar.

Ele tem muita segurança também, comparando com outras marcas também. Esse aspecto eu gosto também. Muita segurança. A nota geral é muito boa, ou 10 (Entrevistado 3).

O que mais que eu sinto é a segurança, eu me sinto muito seguro com o iPhone (Entrevistado 7).

Por ser de arquitetura fechada tem alguns benefícios, principalmente na parte de segurança, então é um produto que você vai usar durante 4 anos e não vai travar, não vai ter vírus, tem facilidade de acessar aplicativos de bancos, é bem seguro realmente; por isso responde à questão de ser de arquitetura fechada; é realmente para proteção do usuário (Entrevistado 11).

As questões referentes a desempenho do produto, mencionada por 11 dos 15 entrevistados demonstra a importância do usuário saber da disponibilidade e rapidez do aparelho em questão. Este emergente atributo, está associado ao valor utilitário e funcional, especialmente sob a perspectiva da eficácia das funções executadas com sucesso, assim o desempenho do iPhone o caracteriza como um protudo no melhor estado da arte da tecnologia (BRUNS; COB, 2014; YEH; WANG; YEH, 2016).

Eu gosto que ele é rápido né. Tu faz uma coisa, tu vira ele que ele já vai, tu abre o aplicativo ele já abre mesmo. Não é aquela coisa que tu tem que ficar esperando para abrir. Tipo, tu clica e já abriu, então eu acho que é uma coisa bem legal nele. Ser bem rápido, tu clica e já faz isso (Entrevistado 2).

Ele só não trava. Nisso ele é muito melhor que a maioria dos outros telefones (Entrevistado 4).

Outro tópico que surgiu durante as entrevistas diz respeito ao status social associado aos usuários de iPhone. Este achado também é defendido por Yeh, Wang e Yeh (2016) cujos resultados sustentam que consumidores, especialmente os mais jovens, valorizam status social associado ao uso de produtos inteligentes, pois estes geram sentimento de pertencimento e promovem relacionamentos interpessoais. 
Às vezes você não precisa nem usar o iPhone para saber se é bom, mas se você tem já te dá um status, sendo que quando você vai falar do seu celular, dificilmente alguém vai falar pega meu celular, quando você tem um iPhone, é pega meu iPhone (Entrevistado 1).

Um iPhone, ele é a definição de um smartphone. Porque ele é feito de forma inteligente, ele se mostra inteligente, sabe, então. É um telefone para pessoas inteligentes. Se ela tem um, isso indica boas coisas sobre ela (Entrevistado 6).

O próprio status que ele te trás, um certo status né. No ser humano tu também procura isso. Tu não vai te meter com alguém que tu tenha uma visão ruim daquilo. 0 celular a mesma coisa. O celular também carrega isso. Essa reputação (Entrevistado 7).

A análise das entrevistas permitiu entender como os usuários de iPhone percebem cada uma das dimensões de inteligência do produto, bem como refletir sobre como se sentem em relação à autonomia, habilidade para aprender, reatividade, habilidade para cooperar, interação humana e personalidade embutidas no aparelho. Os usuários entrevistados também destacaram a segurança, desempenho e status do aparelho e da marca como percepções da inteligência do aparelho. Por isso, o Quadro 5 exibe os principais resultados encontrados. 


\section{Quadro 5 - Principais resultados da pesquisa}

\begin{tabular}{|c|c|}
\hline Dimensão-chave & Principais resultados \\
\hline Autonomia & $\begin{array}{l}\text { O iPhone apresenta todos os níveis de autonomia (desde constante intervenção } \\
\text { humana até totalmente sem intervenção humana). Os usuários gostam de poder } \\
\text { configurar o tomador de decisão. Neste sentido percebe-se a importância e relação da } \\
\text { dimensão autonomia com a capacidade de personalização do produto, pois diferentes } \\
\text { usuários tem preferências de níveis distintos de autonomia. }\end{array}$ \\
\hline $\begin{array}{l}\text { Habilidade para aprender } \\
\text { (adaptabilidade) }\end{array}$ & $\begin{array}{l}\text { Identificou-se que o iPhone aprende por meio de algoritmos e IA como adaptar- } \\
\text { se ao perfil e necessidades do usuário. As atualizações de software melhoram a } \\
\text { desempenho do aparelho e facilitam a interação. Como ponto negativo, destaca-se a } \\
\text { arquitetura fechada e a falta de atualizações para modelos antigos. A aprendizagem é } \\
\text { estabelecida de forma mútua, ou seja, o iPhone aprende com o usuário, assim como o } \\
\text { usuário aprende com e por meio do aparelho. }\end{array}$ \\
\hline Reatividade & $\begin{array}{l}\text { O iPhone reage ao ambiente externo desde que configurações prévias permitam, } \\
\text { sendo a reatividade mais intensa quando associada a funções de business, pois neste } \\
\text { caso permite ações de planejamento e controle. }\end{array}$ \\
\hline Habilidade para cooperar & $\begin{array}{l}\text { Quando utilizado em cooperação com outros aparelhos, as funções do iPhone são } \\
\text { potencializadas, agregando conforto e facilidade aos usuários. A cooperação acontece } \\
\text { entre os usuários. O aparelho também pode ser usado em cooperação com sistemas } \\
\text { de ERP, adicionando valor agregado ao smart product. }\end{array}$ \\
\hline $\begin{array}{l}\text { Interação humana (humanlike } \\
\text { interaction) }\end{array}$ & $\begin{array}{l}\text { Os usuários atribuíram à assistente pessoal, Siri, a capacidade de interação humana. } \\
\text { Sendo que a interação é marcada por diálogo verbal ou em caixas de mensagens } \\
\text { dotadas de humor e inteligência. }\end{array}$ \\
\hline Personalidade & $\begin{array}{l}\text { Os usuários compararam o iPhone a pessoas comunicativas, inteligentes, com } \\
\text { capacidade de tomada de decisão, organizadas, dependentes como um bebê, dotado } \\
\text { de ironia, sarcasmo, humor e empatia. }\end{array}$ \\
\hline Segurança & $\begin{array}{l}\text { Os usuários perceberam a segurança como um diferencial do aparelho analisado em } \\
\text { relação aos outros, inclusive influenciando a compra. A dimensão segurança está } \\
\text { relacionada a habilidade de cooperar com aparelhos da mesma marca, pois cria-se, } \\
\text { no caso dos aparelhos desenvolvidos pela Apple, uma "família fechada" com regras, } \\
\text { protocolos, limites de interoperabilidade com outras marcas, garantindo maior } \\
\text { segurança. }\end{array}$ \\
\hline Desempenho & $\begin{array}{l}\text { Constatou-se que o iPhone possui desempenho superior aos demais aparelhos, seja } \\
\text { por não travar ou por responder rapidamente aos comandos do usuário. }\end{array}$ \\
\hline Status & $\begin{array}{l}\text { Os usuários associam a reputação do iPhone aos usuários, sendo associada a status } \\
\text { social e inteligência. Para usuários jovens, possuir um iPhone pode significar aceitação } \\
\text { a um determinhado grupo social. }\end{array}$ \\
\hline
\end{tabular}

\section{Fonte: Elaborado pelos autores (2017).}

Os resultados exibidos no Quadro 5 estão de acordo com os estudos de Rijsdijk e Hultink (2003) no sentido de que a apreciação da autonomia do produto depende do consumidor. Em adição, os resultados 
desta pesquisa corroboram com Rijsdijk, Hultink e Diamantopoulos (2007), sob a perspectiva de que os consumidores não apreciam produtos inteligentes pela sua própria inteligência, mas por causa da vantagem relativa e compatibilidade que eles oferecem. Entretanto, diferentemente das referências que definem produtos inteligentes com seis dimensões (RIJSDIJK; HULTINK, 2003; RIJSDIJK; HULTINK; DIAMANTOPOULOS, 2007; PARK; LEE, 2014), este trabalho identificou três dimensões adicionais: segurança, desempenho e status. Por isso, a próxima seção apresenta as considerações finais, limitações do estudo e sugestão para estudos futuros.

\section{CONSIDERAÇÕES FINAIS}

Este artigo tinha como objetivo explorar a percepção dos usuários de iPhone quanto às seis dimensões-chave associadas aos produtos inteligentes, o qual foi atingido após a análise de conteúdo das entrevistas realizadas. Percebeu-se que a dimensão com maior referência é a interação humana, já que ocorre constante comunicação entre usuário e aparelho, para que o último possa executar ações necessárias. Das categorias definidas à priori, reatividade e personalidade são as menos referidas pelos entrevistados, sendo que a personalidade geralmente está associada às características da assistente pessoal, Siri.

A contribuiçãa deste estudo para a literatura do tema produtos inteligentes diz respeito às categorias identificadas à posteriori: segurança em tal nível que permite que os usuários acessem contas bancárias e sistemas de ERP; o status social que o produto confere aos seus usuários dando a sensação de serem indivíduos superiores em relação ao resto da sociedade; e desempenho, uma vez que o iPhone está sempre disponivel para o usuário e responde às solicitações com velocidade que atenda às necessidades do mesmo.

Esta pesquisa ainda permitiu refletir, sob a perpectiva do que representa um produto inteligente para o usuário, neste caso o usuário de iPhone, e propor que estes objetos são uma espécie de extensão do corpo e mente das pessoas. Esta ideia está suportada nos seguintes aspectos da interface usuárioproduto: forma com que as pessoas interagem e convivem; dependência recíproca entre usuário e produto; necessidade de melhoria na qualidade de vida das pessoas; status social proporcionado; e colaboratividade. De fato, esta abordagem pode gerar diversas possibilidades de pesquisa futuras sob a perspectiva de entender o impacto social e cultural destas tecnologias na vida das pessoas.

Esta pesquisa destaca a falta de percepção da inteligência embarcada por parte de alguns dos usuários em relação ao iPhone, simplesmente não reconhecendo funcionalidades que foram discriminadas por outros entrevistados. Os próprios usuários admitiram não pensar a respeito da inteligência associada às 
facilidades proporcionadas pelo aparelho. De fato, esta constatação representa uma implicação gerencial, sendo assim, sugere-se às empresas que no desenvolvimento de produtos inteligentes utilizem mais capacidades autoexplicativas, dado que os usuários não entendem como necessária a leitura de manuais para conhecer e explorar melhor os produtos inteligentes.

Ainda considerando as implicações gerencias, sugere-se que novos produtos inteligentes consigam detectar o nivel adequado de autonomia e customizar automaticamente as configurações de acordo com o perfil de cada usuário. Para tanto, a capacidade dos produtos inteligentes em incorporar inteligência artificial é determinante para a melhoria da percepção e desempenho das dimensões dos produtos inteligentes. De fato, a apropriação dos perfis individuais dos usuários por parte dos smartphones é fator preponderante para que os desenvolvedores de produtos inteligentes obtenham vantagem em relação aos seus competidores.

Ao final, observam-se algumas limitações da pesquisa, destacando-se a região onde as entrevistas foram realizadas, sul do Brasil, o que não permite torná-la universal. Entretanto, a heterogeneidade do grupo pesquisados em termos de idade, nível de renda e escolaridade pode compensar as limitações geográficas da pesquisa. Além disso, pode-se apontar como limitação a escolha de uma marca especifica de produto inteligente, o iPhone, como objeto de pesquisa.

Em relação à possibilidade de pesquisas futuras, sugere-se que outros estudos qualitativos e quantitativos confirmem as três novas categorias destacadas pelos entrevistados, além de fortalecer o entendimento da percepção do usuário quanto a inteligência do produto. Destaca-se, também, que este tipo de produto representa preferência por parte dos consumidores, sendo assim uma oportunidade de negócio para desenvolvedores eentrantes no mercado de produtos inteligentes. Partindo das extrapolações mencionadas, sugere-se que futuras pesquisas confirmem quais condições devem ser satisfeitas para que produtos inteligentes sejam percebidos pelo usuário como extensões do próprio corpo.

\section{REFERÊNCIAS}

AITENBICHLER, Erwin et al. Engineering intuitive and self-explanatory smart products. In: Proceedings of the 2007 ACM symposium on Applied computing. ACM, 2007. p. 1632-1637.

AL MUTAWA, Noora; BAGGILI, Ibrahim; MARRINGTON, Andrew. Forensic analysis of social networking applications on mobile devices. Digital Investigation, v. 9, p. S24-S33, 2012.

BABER, C. Humans, servants and agents: human factors of intelligent domestic products. 1996. 
BAUER, Martin W.; GASKELL, George (Ed.). Qualitative researching with text, image and sound: A practical handbook for social research. Sage, 2000.

BARDIN, Lawrence. Análise de conteúdo. Lisboa: edições, v. 70. 2006.

BARLOW, James et al. Choice and delivery in housebuilding: lessons from Japan for UK housebuilders. Building research \& information, v. 31, n. 2, p. 134-145, 2003.

BERTELSMEIER, Fabian; TRÄCHTLER, Ansgar. Decentralized controller reconfiguration strategies for hybrid system dynamics based on product-intelligence. In: Emerging Technologies \& Factory Automation (ETFA), 2015 IEEE 20th Conference on. IEEE, 2015. p. 1-8.

BRUNS, Katherina; JACOB, Frank. Value-in-use and mobile technologies. Business \& Information Systems Engineering, v. 6, n. 6, p. 349-359, 2014.

CASSELL, Justine; THORISSON, Kristinn R. The power of a nod and a glance: Envelope vs. emotional feedback in animated conversational agents. Applied Artificial Intelligence, v. 13, n. 4-5, p. 519-538, 1999.

COMSTOCK, Mica; JOHANSEN, Kerstin; WINROTH, Mats. From mass production to mass customization: enabling perspectives from the Swedish mobile telephone industry. Production Planning \& Control, v. 15, n. 4, p. 362-372, 2004.

CRESWELL, John W. Research design: Qualitative, quantitative, and mixed methods approaches. Sage publications, 2013.

CHRISTENSEN, Jason H. Using RESTful web-services and cloud computing to create next generation mobile applications. In: Proceedings of the 24th ACM SIGPLAN conference companion on Object oriented programming systems languages and applications. ACM, 2009. p. 627-634.

EISENHARDT, Kathleen M.; GRAEBNER, Melissa E. Theory building from cases: Opportunities and challenges. Academy of management journal, v. 50, n. 1, p. 25-32, 2007.

FLICK, U. Introdução à pesquisa qualitativa. 3.ed. Porto Alegre: Artmed, 2009.

KÄRKKÄINEN, Mikko et al. Intelligent products—a step towards a more effective project delivery chain. Computers in industry, v. 50, n. 2, p. 141-151, 2003.

KIRITSIS, Dimitris. Closed-loop PLM for intelligent products in the era of the Internet of things. Computer-Aided Design, v. 43, n. 5, p. 479-501, 2011. 
KOOTI, Farshad et al. iPhone's Digital Marketplace: Characterizing the Big Spenders. In: Proceedings of the Tenth ACM International Conference on Web Search and Data Mining. ACM, 2017. p. 13-21.

LASI, Heiner et al. Industry 4.0. Business \& Information Systems Engineering, v. 6, n. 4, p. 239-242, 2014

LEE, J.-H.; KIM, C.-O. Multi-agent systems applications in manufacturing systems and supply chain management: a review paper. International Journal of Production Research, v. 46, n. 1, p. 233-265, 2008.

LI, Taofen; GUO, Peng; YANG, Shuili. Research on the Backward Customization Mode and its Operational Framework of Intelligent Product. Procedia CIRP, v. 56, p. 401-405, 2016.

LEE, Won-jun. The Empirical Research on the Relationship between Smart Product Characteristics and Customer Satisfaction. International Information Institute (Tokyo). Information, v. 17, n. 9 (A), p. 4017, 2014.

LOWRES, Nicole et al. Feasibility and cost-effectiveness of stroke prevention through community screening for atrial fibrillation using iPhone ECG in pharmacies. The SEARCH-AF study. Thromb Haemost, v. 111, n. 6, p. 1167-76, 2014.

LU, R. F.; PETERSEN, T. D.; STORCH, R. L. Asynchronous stochastic learning curve effects in engineering-to-order customisation processes. International Journal of Production Research, v. 47, n. 5, p. 1309-1329, 2009.

MAASS, Wolfgang; VARSHNEY, Upkar. Preface to the focus theme section:'Smart products'. Electronic Markets, v. 18, n. 3, p. 211-215, 2008.

MALHOTRA, Naresh K. et al. Introdução à pesquisa de marketing. São Paulo: Pearson, 2005.

MANI, Zied; CHOUK, Inès. Drivers of consumers' resistance to smart products. Journal of Marketing Management, v. 33, n. 1-2, p. 76-97, 2017.

MAYRING, Philipp. Qualitative content analysis: theoretical foundation, basic procedures and software solution. 2014.

MEIRELES, Greice Pinto; FEITOSA, Sara Alves. SEGURANÇA DE DADOS: UMA DIMENSÃO PARA UM AMBIENTE URBANO CRIATIVO E INTELIGENTE. Revista Gestão e Desenvolvimento, v. 16, n. 2, p. 122-144, 2019. 
MEYER, Gerben G.; FRÄMLING, Kary; HOLMSTRÖM, Jan. Intelligent products: A survey. Computers in industry, v. 60, n. 3, p. 137-148, 2009.

MCFARLANE, Duncan et al. Auto ID systems and intelligent manufacturing control. Engineering Applications of Artificial Intelligence, v. 16, n. 4, p. 365-376, 2003.

MOZZATO, Anelise Rebelato; GRZYBOVSKI, Denize; TEIXEIRA, Alex Niche. Análises qualitativas nos estudos organizacionais: as vantagens No uso do software nvivo ${ }^{\circledR}$. Revista Alcance (Online), v. 23, n. 4, p. 578, 2016.

OSTGATHE, Martin; ZAEH, Michael F. System for product-based control of production processes. In: Computational Intelligence in Production and Logistics Systems (CIPLS), 2013 IEEE Workshop on. IEEE, 2013. p. 138-144.

PAPETTI, Alessandra et al. Smart objects: an evaluation of the present state based on user needs. In: International Conference on Distributed, Ambient and Pervasive Interactions. Springer, Cham, 2014. p. 359-368.

PARK, Hyun Jung; LEE, Hyung Seok. Product smartness and use-diffusion of smart products: the mediating roles of consumption values. Asian Social Science, v. 10, n. 3, p. 54, 2014.

RIJSDIJK, Serge A.; HULTINK, Erik Jan. "Honey, have you seen our hamster?" Consumer evaluations of autonomous domestic products. Journal of Product Innovation Management, v. 20, n. 3, p. 204-216, 2003.

RIJSDIJK, Serge A.; HULTINK, Erik Jan; DIAMANTOPOULOS, Adamantios. Product intelligence: its conceptualization, measurement and impact on consumer satisfaction. Journal of the Academy of Marketing Science, v. 35, n. 3, p. 340-356, 2007.

RIJSDIJK, Serge A.; HULTINK, Erik Jan. How today's consumers perceive tomorrow's smart products. Journal of Product Innovation Management, v. 26, n. 1, p. 24-42, 2009.

STAKE, Robert E. Qualitative research: Studying how things work. Guilford Press, 2010.

STATISTA: the statistics portal. Disponivel em: <https://www.statista.com/statistics/263401/global-apple-iphone-sales-since-3rd-quarter-2007/>. Acesso em: 07 jul. 2017.

STATISTA: the statistics portal. Disponivel em: <https://www.statista.com/statistics/264875/brand-value-of-the-25-most-valuable-brands/>. Acesso em: 07 jul. 2017. 
SCHMIDT, Rainer et al. Industry 4.0-potentials for creating smart products: empirical research results. In: International Conference on Business Information Systems. Springer, Cham, 2015. p. 16-27.

STÄNDER, Marcus. Bridging the gap between users and smart products. In: Pervasive Computing and Communications Workshops (PERCOM Workshops), 2010 8th IEEE International Conference on. IEEE, 2010. p. 859-860.

VENTÄ, Olli. Intelligent products and systems: Technology theme-final report. VTT Technical Research Centre of Finland, 2007.

WERNER, Steffan Macali; FRAZZON, Enzo Morosini; FORCELLINI, Fernando Antônio. Análise da Implementação de Sistemas Inteligentes para a Gestão da Alta Hospitalar. Revista Gestão e Desenvolvimento, v. 16, n. 1, p. 129-151, 2019.

WONG, Chien Yaw et al. The intelligent product driven supply chain. In: Systems, Man and Cybernetics, 2002 IEEE International Conference On. IEEE, 2002. p. 6 pp. vol. 4.

YEH, Ching-Hsuan; WANG, Yi-Shun; YIEH, Kaili. Predicting smartphone brand loyalty: Consumer value and consumer-brand identification perspectives. International Journal of Information Management, v. 36, n. 3, p. 245-257, 2016.

YIN, Robert K. Estudo de Caso: Planejamento e Métodos. Bookman editora, 2015. 


\section{Apêndice A - Roteiro Semiestruturado}

\begin{tabular}{|c|c|c|}
\hline $\begin{array}{l}\text { Dimensão } \\
\text { analisada }\end{array}$ & Caracterização da dimensão & Questões relativas a esta dimensão \\
\hline 1 - Autonomia & $\begin{array}{l}\text { A autonomia do produto está } \\
\text { relacionada a capacidade do } \\
\text { produto entrar em ação sem } \\
\text { intervenção humana, com pouca } \\
\text { intervenção humana ou com } \\
\text { constante intervenção humana. }\end{array}$ & $\begin{array}{l}\text { 1. Este produto define por conta própria como conduzir tarefas e/ou } \\
\text { atividades? Em caso afirmativo, como é este processo? } \\
\text { 2. Este produto toma decisões sozinho? Favor explicar: } \\
\text { 3. Você já percebeu alguma situação na qual este produto tomou } \\
\text { iniciativa? De que forma isto aconteceu? } \\
\text { 4. Este produto executa ações por conta própria? Poderias exemplificar? }\end{array}$ \\
\hline $\begin{array}{l}2 \text { - Habilidade } \\
\text { para aprender } \\
\text { (adaptabilidade) }\end{array}$ & $\begin{array}{l}\text { Considera-se a habilidade para } \\
\text { aprender como a adaptabilidade } \\
\text { que o produto inteligente } \\
\text { possui e que ao longo do tempo } \\
\text { permite que o produto se adapte } \\
\text { não somente as condições do } \\
\text { ambiente, como também as } \\
\text { necessidades do usuário. }\end{array}$ & $\begin{array}{l}\text { 5. Este produto tem capacidade de aprender? Como você percebe isto? } \\
\text { 6. O desempenho deste produto é melhorado ao longo do tempo? } \\
\text { Favor descrever se o produto executa melhor e mais tarefas à medida } \\
\text { em que você o continua usando. } \\
\text { 7. De que forma este produto aprende com base em sua própria } \\
\text { experiência de uso? } \\
\text { 8. Este produto continuamente se adapta ao ambiente e ao usuário? } \\
\text { Como você detecta isto? }\end{array}$ \\
\hline 3 - Reatividade & $\begin{array}{l}\text { Permite ao produto inteligente } \\
\text { reagir às condições do ambiente } \\
\text { externo, entretanto or produto } \\
\text { toma essa decisão baseado } \\
\text { somente na condição atual do } \\
\text { ambiente. Refere-se a habilidade } \\
\text { em perceber o ambiente e reagir } \\
\text { a ele. }\end{array}$ & $\begin{array}{l}\text { 9. O produto age baseado em percepções? De que forma o produto } \\
\text { percebe o ambiente ou a sua forma de utilizá-lo? } \\
\text { 10. O produto monitora o ambiente, como se ficasse de "olho", } \\
\text { observando? Quais dispositivos proporcionam esta capacidade ao } \\
\text { produto? } \\
\text { 11. Descreva como o produto reage a mudanças no ambiente? } \\
\text { 12 O produto prontamente adapta o seu comportamento ao ambiente? } \\
\text { Explique como ele consegui isto ou como você percebe isto? }\end{array}$ \\
\hline $\begin{array}{l}4 \text { - Habilidade } \\
\text { para cooperar }\end{array}$ & $\begin{array}{l}\text { Refere-se a capacidade de } \\
\text { união dos produtos inteligentes } \\
\text { de forma a atingir um objetivo } \\
\text { comum, sendo essa habilidade } \\
\text { já existente em computadores } \\
\text { e seus periféricos. Ou no caso } \\
\text { dos celulares que podem ser } \\
\text { usados como modem para um } \\
\text { computador. }\end{array}$ & $\begin{array}{l}\text { 13. O referido produto consegue cooperar com outros produtos? Em } \\
\text { que tarefas e/ou ações você percebe isto? } \\
\text { 14. Além da cooperação, de que forma a comunicação se estabelece } \\
\text { entre este produto e outro produto? Favor comentar: } \\
\text { 15. Como é o processo de conexão deste produto com outros produtos? } \\
\text { 16. Em que aspectos este produto trabalha (ou funciona) melhor em } \\
\text { cooperação com outros produtos? }\end{array}$ \\
\hline
\end{tabular}




\begin{tabular}{|c|c|c|}
\hline $\begin{array}{l}5 \text { - Interação } \\
\text { humana } \\
\text { (humanlike } \\
\text { interaction) }\end{array}$ & $\begin{array}{l}\text { A dimensão de interação humana } \\
\text { trata do nível da capacidade que } \\
\text { os produtos inteligentes possuem } \\
\text { para comunicarem-se com os } \\
\text { usuários de forma natural e } \\
\text { semelhante ao discurso humano. }\end{array}$ & $\begin{array}{l}\text { 17. Durante a sua interação com o produto, como este produto te } \\
\text { consulta ou solicita informações? } \\
\text { 18. As ações e/ou tarefas sugeridas pelo produto te ajudam de uma } \\
\text { forma geral? Descreva quais tipos de ajuda você percebe como úteis: } \\
\text { 19. É possivel "dialogar" com o produto? Em que momentos isto } \\
\text { ocorre? Favor exemplificar: } \\
\text { 20. O produto explica para você como dever ser utilizado? As explicações } \\
\text { são claras e úteis? } \\
\text { 21. Como o produto explica o que está executando? }\end{array}$ \\
\hline $\begin{array}{l}6- \\
\text { Personalidade }\end{array}$ & $\begin{array}{l}\text { A dimensão da personalidade } \\
\text { classifica a capacidade do } \\
\text { produto inteligente demonstrar } \\
\text { personalidade estado emocional } \\
\text { de forma convincente para o } \\
\text { usuário. }\end{array}$ & $\begin{array}{l}\text { 22. Na sua percepção, este produto tem propriedades parecidas com } \\
\text { os seres humanos? Favor comentar: } \\
\text { 23. Poderias descrever características de "caráter humano" neste } \\
\text { produto? } \\
\text { 24. De alguma forma, este produto te lembra uma pessoa? Em caso } \\
\text { afirmativo, em que sentido? } \\
\text { 25. Quanto ao comportamento do produto, descreva semelhanças com } \\
\text { o comportamento do produto e de um ser humano: }\end{array}$ \\
\hline & & 26. Gostarias de fazer mais algum comentário? \\
\hline
\end{tabular}

\section{Perfil do Entrevistado}

27. Gênero: ( ) Feminino ( ) Masculino

28. Idade: anos

29. Uso do Produto: ( ) Trabalho ( ) Lazer ( )Ambos Outro:

30. A quanto tempo usa o produto?

31. Ocupação (cargo ou função):

32. Grau de Escolaridade:

33. Nivel de Renda Mensal Individual:

( ) Até $\mathrm{R} \$ 927,00$

( ) Entre $R \$ 928,00$ e $R \$ 1854,00$

( ) Entre $\mathrm{R} \$ 1855,00$ e $\mathrm{R} \$ 2781,00$

( ) Entre $R \$ 2782,00$ e $R \$ 3708,00$

( ) Entre 3709,00 e R\$4635,00

( ) Entre $\mathrm{R} \$ 4636,00$ e $\mathrm{R} \$ 5562,00$

( ) Entre $R \$ 5563,00$ e $R \$ 6489,00$

( ) Mais de $\mathrm{R} \$ 6489,00$ 